\title{
Treatment of COPD Groups GOLD A and B with Inhaled Corticosteroids in the COSYCONET Cohort - Determinants and Consequences
}

This article was published in the following Dove Press journal: International Journal of Chronic Obstructive Pulmonary Disease

Johanna I Lutter, (iD) ' Rudolf A Jörres, (iD) ${ }^{2}$ Franziska C Trudzinski, (iD) ${ }^{3}$ Peter Alter, (iD ${ }^{4}$ Christina Kellerer, ${ }^{2,5}$ Henrik Watz, ${ }^{6}$ Tobias Welte, (iD) ${ }^{7}$ Robert Bals, ${ }^{8}$ Diego Kauffmann-Guerrero, (iD) Jürgen Behr, ${ }^{9}$ Rolf Holle, (iD) ${ }^{10}$ Claus F Vogelmeier, ${ }^{4}$ Kathrin Kahnert ${ }^{9}$

On behalf of the COSYCONET study group

'Institute of Health Economics and Health Care Management, Helmholtz Zentrum München GmbH - German Research Center for Environmental Health, Comprehensive Pneumology Center Munich (CPC-M), Member of the German Center for Lung Research, Munich, Germany; ${ }^{2}$ Institute and Outpatient Clinic for Occupational, Social and Environmental Medicine, LMU Hospital, Comprehensive Pneumology Center Munich (CPC-M), Munich, Germany; ${ }^{3}$ Department of Pneumology and Critical Care Medicine, Thoraxklinik University of Heidelberg, Translational Lung Research Center Heidelberg (TLRC-H), Member of the German Center for Lung Research (DZL), Heidelberg, Germany;

${ }^{4}$ Department of Medicine, Pulmonary and Critical Care Medicine, University Medical Center Giessen and Marburg, Philipps-University Marburg (UMR), Germany, Member of the German Center for Lung Research (DZL), Marburg, Germany; ${ }^{5}$ School of Medicine, Institute of General Practice and Health Services Research, Technical University of Munich (TUM), Munich, Germany; ${ }^{6}$ Pulmonary Research Institute at LungenClinic Grosshansdorf, Airway Research Center North (ARCN), Member of the German Center for Lung Research (DZL), Grosshansdorf, Germany; ${ }^{7}$ Department of Pneumology, Hannover Medical School, Hannover, Germany; ${ }^{8}$ Department of Internal Medicine V - Pulmonology, Allergology, Respiratory Intensive Care Medicine, Saarland University Hospital, Homburg, Germany; ${ }^{9}$ Department of Medicine V, University of Munich (LMU), Comprehensive Pneumology Center, Member of the German Center for Lung Research (DZL), Munich, Germany; ${ }^{1}$ Institute for Medical Informatics, Biometry and Epidemiology, LMU Hospital, Munich, Germany

Correspondence: Kathrin Kahnert Department of Internal Medicine V, University of Munich (LMU), LMU Hospital, Ziemssenstraße I, Munich, 80336, Germany

Email Kathrin.Kahnert@med.unimuenchen.de
Background: In COPD patients of GOLD groups A and B, a high degree of treatment with inhaled corticosteroids (ICS) has been reported, which is regarded as overtreatment according to GOLD recommendations. We investigated which factors predict ICS use and which relationship it has to clinical and functional outcomes, or healthcare costs.

Methods: We used pooled data from visits 1 and 3 of the COSYCONET cohort $(n=2741$, $\mathrm{n}=2053$, interval 1.5 years) including patients categorized as GOLD grades $1-4$ and GOLD group A or B at both visits $(n=1080)$. Comparisons were performed using ANOVA, and regression analyses using propensity matching and inverse probability weighting to adjust for differences between ICS groups. These were defined as having ICS at both visits (always) vs no ICS at both visits (never). Measures were divided into predictors of ICS treatment and outcomes.

Results: Among 1080 patients, 608 patients were eligible for ICS groups $(n=297$ never, $\mathrm{n}=311$ always). Prior to matching, patients with ICS showed significantly $(\mathrm{p}<0.05$ each) impaired lung function, symptoms and exacerbation history. After matching, the outcomes generic quality of life and CO diffusing capacity were increased in ICS patients $(\mathrm{p}<0.05$ each). Moreover, costs for respiratory medication, but not total health care costs, were significantly elevated in the ICS group by $780 €$ per year.

Conclusion: ICS therapy in COPD GOLD A/B patients can have small positive and negative effects on clinical outcomes and health care costs, indicating that the clinical evaluation of ICS over-therapy in COPD requires a multi-dimensional approach.

Keywords: COPD, inhaled corticosteroids, GOLD groups, overtreatment

\section{Introduction}

In recent years, a number of studies revealed a high degree of overtreatment with respiratory medication, in particular with inhaled corticosteroids (ICS), in patients with COPD and especially in GOLD groups $\mathrm{A}$ and $\mathrm{B} .^{1-5}$ Despite the narrow indication for the prescription of ICS in COPD, their use has been reported in up to $70 \%$ of patients in some European countries, such as Switzerland, Greece, and the UK. ${ }^{6-8}$ In line with this, data from the COSYCONET COPD cohort also showed that about $2 / 3$ of patients received an inhaled corticosteroid, though this would have been indicated in only about 50\% according to GOLD 2017 recommendations. ${ }^{9}$ This is relevant, as ICS have side effects, such as a higher rate of pneumonia, diabetes mellitus, osteoporosis, oropharyngeal candidiasis and hoarseness. $^{10,11}$ Overtreatment also has economic consequences; for the 
Netherlands, for example, savings of 84 million Euro per year have been estimated, if ICS therapy would be reduced to the essential level. ${ }^{12}$

To guide therapeutic decisions, recommendations, such as those given by GOLD, ${ }^{13}$ provide basic orientation but the final decision might depend on additional factors such as drug intolerances and interactions, patients' preferences, impairments in lung function, and comorbidities such as dementia, depression, ${ }^{14,15}$ or cardiac diseases associated with increased symptom burden ${ }^{16}$ but not necessarily higher exacerbation rate.

Based on this, a thorough analysis of data from COPD patients with ICS overtreatment could help to understand, which factors determine the therapeutic decision for ICS, and conversely, which negative, and potentially positive, effects overtreatment has on clinical and functional outcomes. The results of such an analysis might be useful for a refinement of treatment recommendations. We addressed these questions using data of the large and well-characterized multi-center COPD cohort COSYCONET (COPD and Systemic Consequences-Comorbidities Network). ${ }^{17}$

\section{Materials and Methods Study Population}

The present analysis used data of the baseline visit $1(\mathrm{n}=$ $2741)$ and the 18-month follow-up visit $3(n=2053)$ of COSYCONET. Visits took place between 2011 and 2015. The observational COPD cohort study COSYCONET investigates the interaction of lung disease, comorbidities and systemic inflammation. Within COSYCONET, patients aged 40 years and older with a physician-based diagnosis of COPD (according to the GOLD criteria) or chronic bronchitis were included and repeatedly reexamined in 31 study centres across Germany. Further details on recruitment, inclusion/exclusion criteria and the assessment of medication can be found elsewhere. ${ }^{17}$ We only included patients categorized as GOLD grades $1-4^{18}$ and GOLD groups A or B (according to mMRC) at both visits $(n=1080)$. Since for groups A/B in the absence of the comorbidity asthma ICS are considered as overtreatment, we focused our analysis on the A/B groups, further excluding patients with the physician-based diagnosis of asthma ( $\mathrm{n}=133)$ or alpha 1-antitrypsin deficiency $(n=58)$. Patients of GOLD groups C and D were not considered, as in these groups, the use of ICS is not necessarily overtreatment.
The treatment groups used for analysis were based on patients' reports on the intake of ICS at visits 1 and 3 . Patients with ICS at both visits were categorized as "ICS always", those with no intake at both visits as "ICS never". In doing so, a stable ICS use over at least 1.5 years was guaranteed, although the number of patients was reduced.

COSYCONET has been approved by the ethical committees of all study centers, and all patients gave their written informed consent. ${ }^{17}$

\section{Assessments}

The study protocol and procedures of COSYCONET have been described previously. ${ }^{17}$ All assessments were performed under stable conditions and included patients' history, clinical state (mMRC, CAT), quality of life (EQ-VAS), St George's Respiratory Questionnaire (SGRQ), BODE score ${ }^{19}$ and FatFree Mass Index (FFMI), ${ }^{20}$ guided by standard operating procedures. ${ }^{17}$ Physical capacity and activity were evaluated using the 6-Minute-Walking Distance (6-MWD) and the International Physical Activity Questionnaire (IPAQ). ${ }^{21}$ The identification of comorbidities was based on patients' reports of physician-based diagnoses, combined with the intake of disease-specific medication. ${ }^{22}$ Lung function assessments obeyed established guidelines. ${ }^{23-25}$ The measures comprised forced expiratory volume in one second $\left(\mathrm{FEV}_{1}\right)$, forced vital capacity (FVC) and their ratio $\left(\mathrm{FEV}_{1} / \mathrm{FVC}\right)$ from spirometry, moreover diffusing capacity for carbon monoxide (CO) in terms of transfer factor (TLCO) and transfer coefficient (KCO), moreover intrathoracic gas volume (ITGV), residual volume (RV), total lung capacity (TLC) and the ratio RV/TLC from body plethysmography. Predicted values for spirometry $^{23}$ and diffusing capacity ${ }^{25}$ were taken from the Global Lung Function Initiative (GLI), for body plethysmography from ECSC. ${ }^{26}$

Annual healthcare costs were calculated by multiplying in- and outpatient, rehabilitation and physiotherapy utilization frequencies with German unit costs. The estimation of medication costs was restricted to prescription-only pharmaceuticals and based on information about name, national drug code, defined daily doses, and pharmacy retails prices. All costs were winsorized at the 95th percentile and refer to the price year 2012. Further details on cost estimation have been described elsewhere. ${ }^{27}$

\section{Statistical Analysis}

We performed a combined analysis of visit 1 and 3 data in order to be consistent with the ICS medication groups and to reduce the variability of values while keeping the 
degrees of freedom low. There was no hint on differential loss in the ICS groups over the two visits. Correspondingly, for all outcome parameters (see below), mean values of visit 1 and 3 values were taken. The groups "ICS always" vs "ICS never" were compared using chisquare tests for categorical variables, and analysis of variance (ANOVA) or Kruskal-Wallis tests for continuous variables, depending on the data distribution.

\section{Predictors of ICS Treatment and Inverse Probability of Treatment Weighting}

To identify independent determinants of ICS treatment we considered as potential predictors those variables that are easily available to treating physicians. These included age, $\mathrm{BMI}, \mathrm{FEV}_{1 \%}$ predicted, $\mathrm{FEV}_{1} / \mathrm{FVC}$, exacerbation history (any/none), all eight single CAT items to cover COPD symptoms; for these parameters mean values of visits 1 and 3 were taken. Visit 1 values were chosen as predictors for sex, years since COPD diagnosis, GOLD group based on mMRC, smoking status (active vs former/never), and DemTect and PHQ-9 score to address cognitive impairment and depression which might have influenced the therapeutic decisions.

As patients' characteristics were significantly different between the "never ICS" and "always ICS" groups, we used propensity scores (PS) to adjust for the differences. PS were calculated based on a logistic regression model estimating the probability of receiving ICS on the basis of the predictors mentioned above. In a second step, Inverse Probability of Treatment Weights (IPW) were derived from the PS. As a result, a patient who actually received ICS but had a low probability (PS) for ICS was compared with an untreated patient with equally low PS, as both were similar in clinical characteristics according to their PS. The different PS distributions in the two groups were transformed into statistical weights, enabling a valid comparison between groups. All analyses were performed using SAS software (SAS Institute Inc., Cary, NC, USA, version 9.4), specifically the procedures PSMATCH, LOGISTIC and GENMODE.

\section{Relationship Between ICS Treatment and Outcomes}

As outcomes, we chose variables that we considered as unlikely to be available to or used by the treating physicians for treatment decisions regarding ICS. These comprised disease-specific and generic health-related quality of life (HRQL) assessed by the three domains of the SGRQ as well as the VAS scale, moreover physical capacity in terms of 6-MWD, CO diffusing capacity, the BODE score, FFMI, and health care costs. The outcomes were different from the predictors of treatment and computed using IPW ${ }^{28}$ in generalized linear regression models, whereby a gamma distribution was chosen for the analysis of the skewed cost data. In addition to the binary ICS variable (always vs never), the covariates from the logistic regression were included for maximal adjustment.

\section{Sensitivity Analyses}

We performed several sensitivity analyses to test for the robustness of results regarding the relationship between ICS and outcomes. First, models were recalculated including patients with a physician-based diagnosis of asthma. Second, we excluded patients who reported the intake of oral corticosteroids (OCS). Third, the definition of ICS groups was altered by comparing "always" vs its complement "not-always", and of "never" vs its complement "not-never".

\section{Results}

\section{Baseline Characteristics}

Following the in- and exclusion criteria, 608 patients were of group A or B at both visits, whereby 297 had never ICS and 311 always ICS (Table 1, Figure 1). Unadjusted differences between both groups were significant ( $p<0.05$ each) for age, smoking status, years since diagnosis, distribution of GOLD groups, exacerbation rates, $\mathrm{FEV}_{1} \%$ predicted, FVC \%predicted, $\mathrm{FEV}_{1} / \mathrm{FVC}$, RV \%predicted, RV/TLC, 6-MWD, SGRQ subscores and total CAT score. This indicated that patients with ICS showed an impaired clinical and functional state compared to patients without ICS. The level of education was not found to differ between groups thus education was not considered as a potential predictor of ICS treatment.

The distribution of comorbidities is shown in Table 2; the only significant difference was that patients with ICS showed a higher proportion of arterial hypertension. Treatment with respiratory medication is shown in Table 3. In the ICS always group, $72 \%$ of patients received a combination of LAMA + LABA + ICS. Regarding unadjusted mean annual healthcare costs (Table 4), patients with ICS had significantly higher total costs $(+340 € /$ year $)$. With respect to separate cost categories, the difference between groups was greatest for costs of respiratory medication (ATC Code "R"), with $+780 € /$ year for the ICS group. On the other hand, patients with ICS showed a trend towards lower inpatient costs $(-100 € /$ year), which was, however, not statistically significant. 
Table I Characteristics of Patients in GOLD Groups A/B Stratified by Treatment with/without ICS

\begin{tabular}{|c|c|c|c|c|}
\hline & & $\begin{array}{l}\text { ICS Never }^{\#} \\
\mathbf{N}=297\end{array}$ & $\begin{array}{c}\text { ICS Always }{ }^{\#} \\
N=3 I I\end{array}$ & p-value \\
\hline Age (y) & & $65.7 \pm 8.4$ & $67.3 \pm 7.6$ & 0.0130 \\
\hline Male & & $187(63.0)$ & $216(69.5)$ & 0.0906 \\
\hline BMI $\left(\mathrm{kg} / \mathrm{m}^{2}\right)$ & & $26.7 \pm 4.8$ & $27.2 \pm 5.1$ & 0.1888 \\
\hline FFMI $\left(\mathrm{kg} / \mathrm{m}^{2}\right)^{+}$ & & $18.4 \pm 2.3$ & $18.4 \pm 2.6$ & 0.9204 \\
\hline \multirow[t]{2}{*}{ Smoking status } & Active & $117(39.4)$ & $65(20.9)$ & $<0.0001$ \\
\hline & Not active * & $180(60.6)$ & $246(79.1)$ & $<0.0001$ \\
\hline \multirow[t]{3}{*}{ Education } & Basic & $157(52.9)$ & $177(56.9)$ & 0.5192 \\
\hline & Secondary & $84(28.3)$ & $76(24.4)$ & \\
\hline & Higher & $56(18.9)$ & $58(18.7)$ & \\
\hline Years since COPD diagnosis & & $5.7 \pm 5.8$ & $8.0 \pm 6.1$ & $<0.0001$ \\
\hline \multirow[t]{2}{*}{ GOLD groups (mMRC) } & A & $218(73.4)$ & $191(61.4)$ & 0.0016 \\
\hline & B & $79(26.6)$ & $120(38.6)$ & \\
\hline $\mathrm{mMRC}^{+}$ & & $1.19 \pm 0.72$ & $1.42 \pm 0.79$ & 0.0001 \\
\hline \multirow[t]{2}{*}{ Exacerbation history } & None & $197(66.3)$ & $158(50.8)$ & 0.0001 \\
\hline & Mild/Moderate & $100(33.7)$ & $153(49.2)$ & \\
\hline FEV , (\%predicted) & & $62.9 \pm 17.3$ & $54.2 \pm 17.6$ & $<0.0001$ \\
\hline FVC (\%predicted) & & $86.8 \pm 16.8$ & $80.1 \pm 16.9$ & $<0.0001$ \\
\hline $\mathrm{FEV}_{1} / \mathrm{FVC}$ & & $72.2 \pm 13.4$ & $67.2 \pm 13.5$ & $<0.0001$ \\
\hline ITGV (\%predicted) & & $140.5 \pm 29.2$ & $144.0 \pm 31.1$ & 0.1551 \\
\hline RV (\%predicted) & & $154.4 \pm 39.4$ & $166.1 \pm 43.2$ & 0.0007 \\
\hline $\mathrm{RV} / \mathrm{TLC}$ & & $123.0 \pm 22.0$ & $132.2 \pm 23.7$ & $<0.0001$ \\
\hline TLCO $(\% p r e d i c t e d)^{+}$ & & $62.0 \pm 19.1$ & $59.5 \pm 21.5$ & 0.1351 \\
\hline KCO (\%predicted) ${ }^{+}$ & & $67.1 \pm 24.1$ & $68.2 \pm 25.0$ & 0.5718 \\
\hline OCS & & $12(4.0)$ & $24(7.7)$ & 0.0549 \\
\hline DemTect & & $15.4 \pm 2.8$ & $15.4 \pm 2.7$ & 0.8905 \\
\hline PHQ-9 & & $4.8 \pm 3.9$ & $5.1 \pm 4.0$ & 0.2480 \\
\hline 6-MWD $(\mathrm{m})^{+}$ & & $466.6 \pm 85.7$ & $433.1 \pm 99.6$ & $<0.0001$ \\
\hline $\mathrm{IPAQ}^{+}$ & & $4808.8 \pm 3777.8$ & $4386.4 \pm 3632.8$ & 0.1632 \\
\hline $\mathrm{BODE}^{+}$ & & $1.31 \pm 1.40$ & $2.14 \pm 1.77$ & $<0.0001$ \\
\hline SGRQ symptoms & & $43.3 \pm 19.6$ & $48.3 \pm 19.6$ & 0.0021 \\
\hline SGRQ activity ${ }^{+}$ & & $44.1 \pm 23.5$ & $51.3 \pm 23.4$ & 0.0002 \\
\hline SGRQ impacts ${ }^{+}$ & & $19.2 \pm 15.2$ & $22.6 \pm 17.4$ & 0.0114 \\
\hline EQ-VAS + & & $65.2 \pm 16.4$ & $62.6 \pm 16.3$ & 0.0603 \\
\hline CAT total score & & $14.2 \pm 6.1$ & $15.9 \pm 6.5$ & 0.0007 \\
\hline
\end{tabular}

Notes: ${ }^{\#}$ ICS always was coded as yes, if a patient reported the intake of ICS at both visits. ICS never was defined as no ICS prescription at both visits. ${ }^{+}$Used as outcome; other variables were use as predictors of treatment with ICS. *Ex- or never-smoker. Mean values and standard deviations, as well as absolute numbers are given. Comparisons between groups were performed by chi-square tests, ANOVA and Kruskal-Wallis tests, as appropriate. 


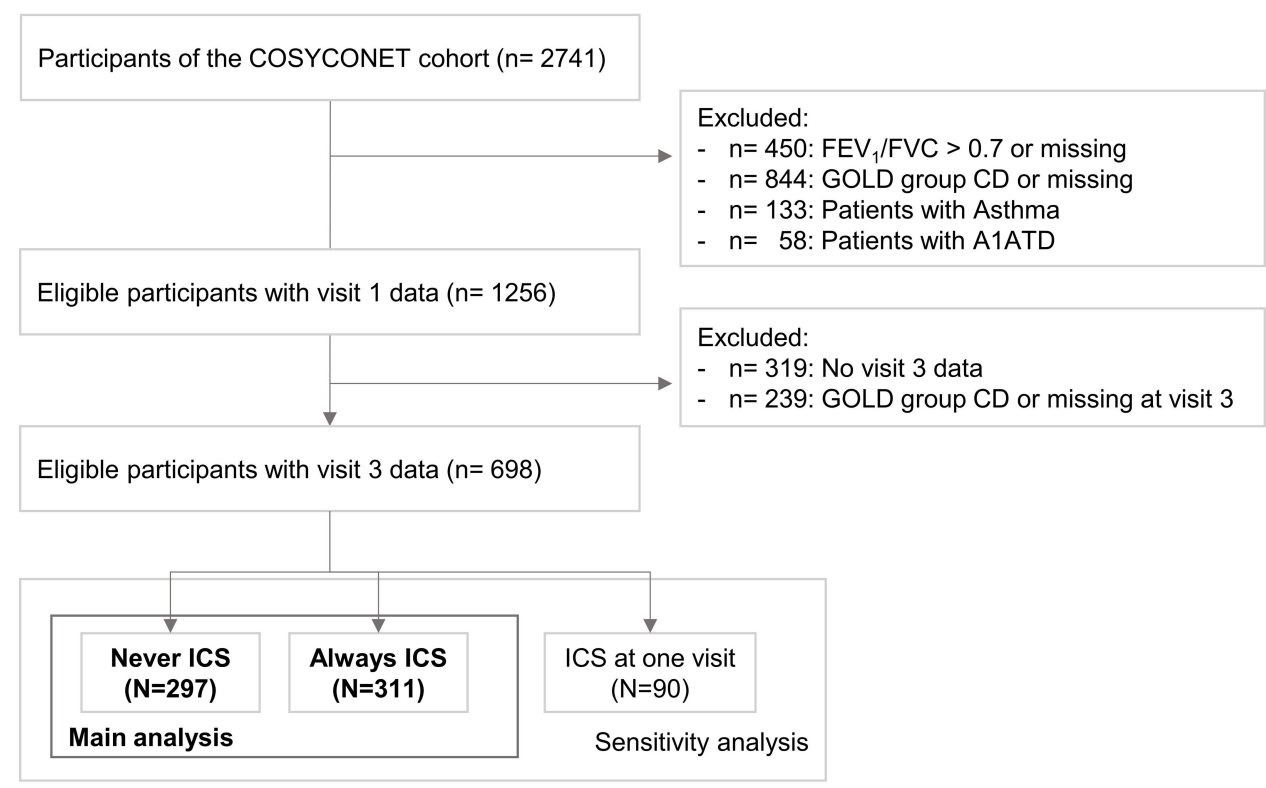

Figure I Consort diagram of the study population.

\section{Predictors of ICS Use}

Among the variables included as potential predictors of ICS therapy, active smoking, having had a mild or moderate exacerbation, lower $\mathrm{FEV}_{1} \%$ predicted, a longer time since diagnosis, higher scores of CAT item 2 (phlegm) and higher PHQ9 score, as well as lower scores of CAT items 3 (chest tightness) and 8 (energy) turned out to be significant (Table S1). Figure 2 illustrates the standardized mean differences between the two ICS groups before and after applying the IPW matching. It can be seen that after the weighting process differences were lower than 0.25 , which is generally considered as the maximum acceptable bound to assure comparability; they even satisfied the stronger requirement of being $<0.1$. Thus, the matching procedure was successful and ensured statistical comparability between groups.

\section{Comparison of Outcome Measures Regarding ICS Treatment}

Table 5 shows the associations between ICS treatment and outcome measures expressed as differences between ICS groups after IPW-based adjustment for differences in patient characteristics. ICS was associated with higher EQ-VAS $(\mathrm{p}=0.0163)$ and higher TLCO \%predicted $(\mathrm{p}=0.0030)$. Furthermore, there was a trend $(\mathrm{p}<0.10)$ towards higher $\mathrm{KCO}$ and lower FFMI in patients treated with ICS.

Regarding annual direct healthcare costs, the results are shown in Figure 3. The difference in total direct costs (see Table 4) was no longer significant after IPW-based adjustment. In contrast, ICS was associated with 1.31-times higher total medication costs, specifically with 1.79-times higher costs for respiratory medication $(\mathrm{p}<0.05$ each).

Table 2 Prevalence of Comorbidities

\begin{tabular}{|c|c|c|c|}
\hline & $\begin{array}{c}\text { ICS Never } \\
\mathbf{N}=297\end{array}$ & $\begin{array}{c}\text { ICS Always } \\
\mathbf{N}=3 I I\end{array}$ & p-value \\
\hline Diabetes & $32(10.8)$ & $39(12.5)$ & 0.4980 \\
\hline Gastrointestinal disorders * & $112(37.7)$ & $117(37.6)$ & 0.9818 \\
\hline Hyperuricemia & $39(13.1)$ & $58(18.7)$ & 0.0633 \\
\hline Hyperlipoproteinemia & $126(42.4)$ & $133(42.8)$ & 0.9323 \\
\hline Osteoporosis $*$ & $30(10.1)$ & $35(11.3)$ & 0.6456 \\
\hline Hypertension * & $154(51.9)$ & $186(59.8)$ & 0.0483 \\
\hline Cardiac disease ${ }^{\#}$ & $65(21.9)$ & $58(18.7)$ & 0.3208 \\
\hline
\end{tabular}

Notes: *Self-reported information was combined with disease-specific medication. ${ }^{\#}$ At least one out of: Coronary artery disease, heart failure, myocardial infarction. Absolute numbers and percentages are given. p-values refer to the comparison between patients without and with ICS and were derived from Chi-square statistics. 
Table 3 Treatment with Respiratory Medication

\begin{tabular}{|l|c|c|}
\hline & $\begin{array}{c}\text { ICS Never } \\
\mathbf{N}=\mathbf{2 9 7}\end{array}$ & $\begin{array}{c}\text { ICS Always } \\
\mathbf{N}=\mathbf{3} \text { I I }\end{array}$ \\
\hline No respiratory medication & $83(27.9)$ & \\
Only LAMA & $62(20.9)$ & \\
Only LABA & $46(15.5)$ & \\
LAMA + LABA & $106(35.7)$ & \\
Only ICS & & $4(1.3)$ \\
LAMA + ICS & & $9(2.9)$ \\
LABA + ICS & & $74(23.8)$ \\
LAMA + LABA + ICS & & $224(72.0)$ \\
\hline
\end{tabular}

Notes: Absolute numbers and row percentages are given. All numbers are based on information assessed at visit $\mathrm{I}$.

Table 4 Mean Annual Direct Healthcare Costs in $€$

\begin{tabular}{|l|c|c|l|}
\hline & $\begin{array}{c}\text { ICS Never } \\
\mathbf{N}=\mathbf{2 9 7}\end{array}$ & $\begin{array}{c}\text { ICS Always } \\
\mathbf{N}=\mathbf{3} \text { I I }\end{array}$ & p-value \\
\hline Total direct costs & $4206 \pm 4854$ & $4547 \pm 3822$ & $<0.000 \mathrm{I}$ \\
Medication costs* & $1490 \pm 1286$ & $2191 \pm 1004$ & $<0.000 \mathrm{I}$ \\
$\quad$ Respiratory medication & $750 \pm 488$ & $1528 \pm 495$ & $<0.000 \mathrm{I}$ \\
Other medication & $740 \pm 1143$ & $663 \pm 826$ & 0.4162 \\
Inpatient costs & $1336 \pm 2437$ & $1224 \pm 23$ I2 & 0.9826 \\
Outpatient costs & $616 \pm 459$ & $660 \pm 458$ & 0.1844 \\
Rehabilitation costs & $194 \pm 445$ & $20 I \pm 485$ & 0.9733 \\
Physiotherapy costs & $76 \pm 139$ & $79 \pm 143$ & $0.913 \mathrm{I}$ \\
\hline
\end{tabular}

Notes: *Medication costs was restricted to prescription-only pharmaceuticals and based on information about name, national drug code, defined daily doses, and pharmacy retails prices. Mean values and standard deviations are given. $\mathrm{p}$ values were based on Kruskal-Wallis tests. All costs refer to the price year 2012.

\section{Sensitivity Analysis}

When excluding patients with oral steroids, the results remained virtually unchanged regarding magnitude and significance level of effects. Conversely, when including patients with the diagnosis of asthma $(n=133)$, the results were also in accordance with our main analysis, however effect sizes were smaller. Moreover, when using regression models adjusting for all covariates but without using IPW, slightly higher p-values resulted.

In addition to the comparison always vs never ICS, we performed comparisons of always vs not-always, and of never vs not-never. These contrasts were less sharp than that between always vs never but had the advantage that the total data set could be used. Regarding the differences in outcomes, both sensitivity analyses confirmed the results of the always vs never analysis.

\section{Discussion}

The present study had the aim to evaluate determinants and consequences of ICS therapy in COPD patients of GOLD groups $\mathrm{A} / \mathrm{B}$ without the comorbidity asthma, in whom ICS therapy is not generally recommended. ${ }^{29,30}$ Compared to patients without ICS, those receiving ICS showed impairments in a variety of clinical and functional measures. These impairments could be either the reason for the use of ICS, or its consequence, or both. To reveal the effects of ICS therapy under these circumstances, proper adjustment was indispensable. We achieved this by propensity score matching and corresponding weighted regression analysis. The matching used variables that may be argued to have an influence on the decision to prescribe ICS in clinical practice. After matching, nearly all differences in outcome measures between patients with vs without ICS therapy were no more significant. Remarkably, however, generic quality of life and CO diffusing capacity turned out to be slightly improved in association with ICS. The costs for all medication and respiratory medication remained significantly elevated after matching, in contrast to total health care costs. These data indicate that in COPD patients of GOLD A/B groups, ICS therapy might have small positive as well as negative effects on outcomes including health care costs.

In GOLD A/B patients without concomitant asthma, initial treatment with short- or long-acting bronchodilators is commonly considered to be standard of care..$^{29,31}$ This was also true until 2015 when the measurements underlying the present analysis were completed. Recent data demonstrated a high frequency of ICS use in A/B patients in several countries. $^{5-8}$ Among the consequences, increased medication costs have already been addressed. ${ }^{12,32}$ The side effects of ICS are known to depend on dosage and type of ICS (eg fluticasone, budesonide, beclomethasone) and probably occur across all severity grades of $\mathrm{COPD}^{33,34}$ including groups $\mathrm{A} / \mathrm{B}$. This raises the question of the functional consequences of ICS therapy in $\mathrm{A} / \mathrm{B}$ patients but also on potential positive effects, which has not been studied until now.

The analysis was rendered difficult through the fact that patients with ICS therapy showed impairments in many clinical and functional parameters compared to those without ICS. The impairments might have been among the factors leading to the prescription of ICS, or they might be consequences of the prescription. This can only be resolved by adjustment procedures, such as propensity score matching, that aim to achieve comparability between groups.

We distinguished between predictors and outcomes of ICS therapy. As predictors, we chose those measures of which it could be reasonably assumed that they were both available to and used by treating physicians in the decision 

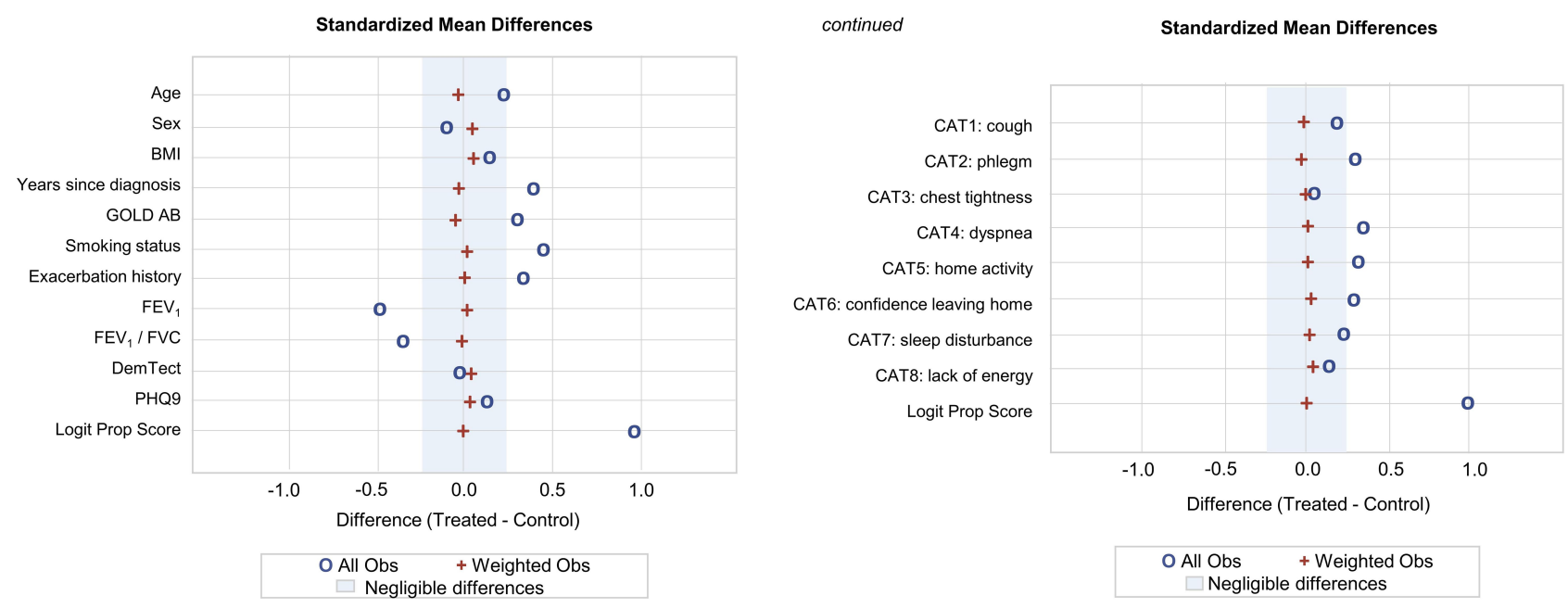

Figure 2 Determinants of ICS therapy before and after weighting. Standardized mean differences of variables were calculated based on propensity scores leading to inverse probability of treatment weights (IPW).

pro vs con ICS. This excluded complex tools such as the SGRQ which we considered useful only as an outcome measure. The same applied to 6-MWD, IPAQ, BODE and FFMI. Regarding CO diffusing capacity, it also seemed not likely that physicians would use this measure for the decision on ICS treatment. Exacerbations (no versus mild/moderate) were only predictors, and severe exacerbations were by definition excluded as they would have led into GOLD $\mathrm{C}$ and $\mathrm{D}$ categories.

The controversy about the usefulness of ICS in COPD is reflected by its cautious consideration in GOLD A/B patients in the most recent recommendations. ${ }^{29}$ In the last years, the decision has often been linked to blood eosinophil counts.
A recent study showed a reduction in exacerbation rate as a function of eosinophilic count: the higher the eosinophilia, the greater the benefit of ICS within triple therapy compared with LAMA/LABA without ICS. ${ }^{35}$ Accordingly, there was a $16 \%$ reduction of hospitalizations due to severe exacerbations by ICS, and in another trial, the reduction of moderate and severe exacerbations by ICS was even $52 \% .{ }^{36}$ These data included group $\mathrm{C}$ and $\mathrm{D}$ patients and were thus not comparable to our data in $\mathrm{A} / \mathrm{B}$ patients. We also did not include eosinophil count as it was available only in 131 patients. A direct comparison of the groups always vs never ICS showed no significant differences $(p=0.16)$ in eosinophil numbers.

Table 5 Association Between ICS and Outcome Measures (Always vs Never)

\begin{tabular}{|l|c|c|c|c|}
\hline Outcomes & Estimate & & $\mathbf{9 5 \%}$ Cl & p-value \\
\hline Health-related quality of life & & & 0.44 to 4.34 & 0.0163 \\
EQ-VAS & 2.39 & -2.50 to 1.41 & 0.5839 \\
SGRQ symptoms & -0.55 & -3.45 to 0.33 & 0.1064 \\
SGRQ activity & -1.56 & -2.55 to 0.48 & 0.1805 \\
SGRQ impacts & -1.04 & & & \\
\hline Diffusion capacity & & $(\uparrow)$ & -0.48 to 6.8 & 0.0030 \\
TLCO (\%predicted) & 3.65 & & -0.41 to 0.00 & 0.0885 \\
KCO (\%predicted) & 3.16 & & & 0.0502 \\
\hline Fat free mass index & -0.20 & & -13.79 to 8.96 & \\
\hline Physical activity & & & -544.22 to 591.0 & 0.6768 \\
6-MWD & -2.42 & & & 0.9355 \\
IPAQ & 23.43 & & & \\
\hline
\end{tabular}

Notes: Estimates with $95 \% \mathrm{Cl}$ for the variable ICS=always are shown. Each row represents a separate linear regression model, adjusted for covariates and including the IPW (based on propensity scores). The symbol next to the estimate indicates the direction of change for estimates with $p<0.05$ : $\uparrow$ improvement of outcome, $\downarrow$ deterioration of outcome. 


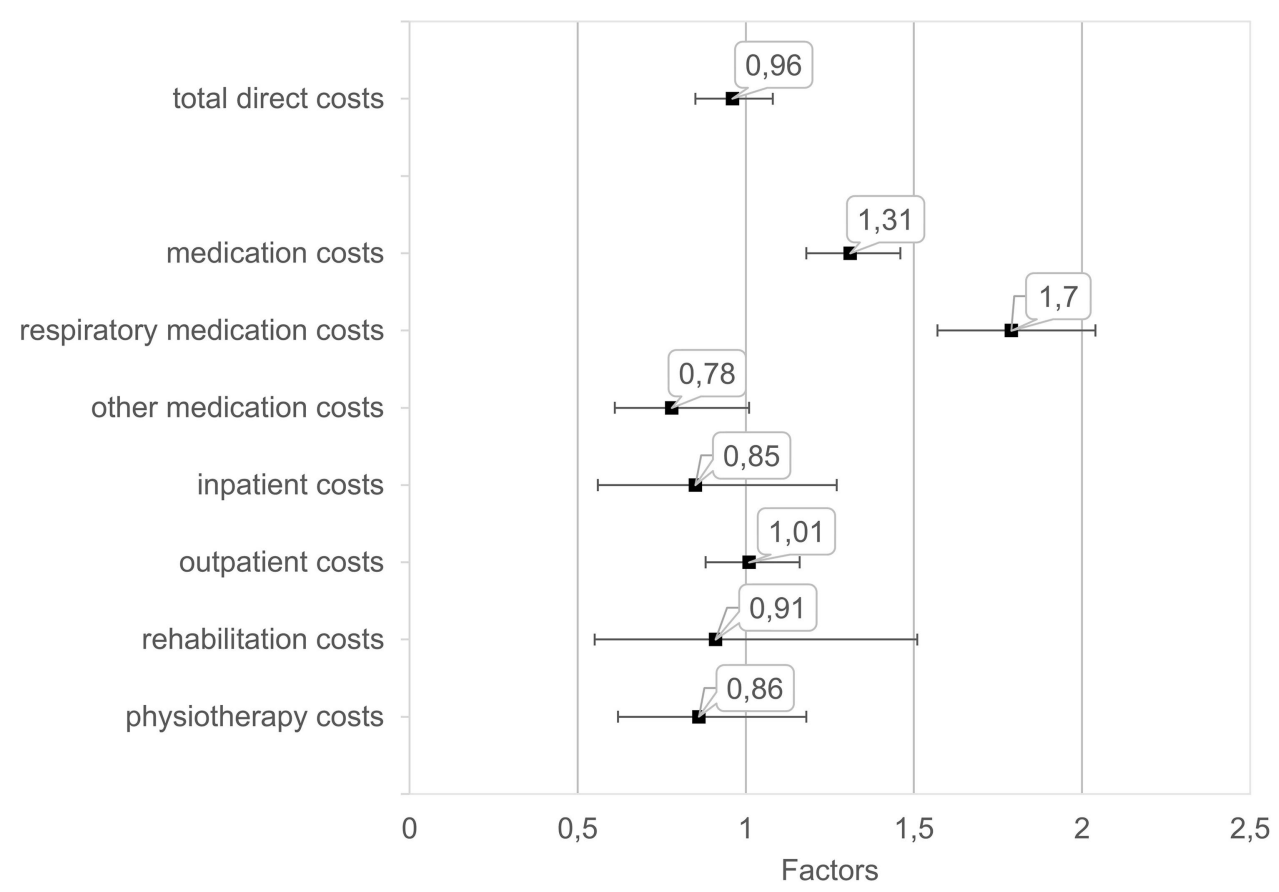

Figure 3 Effect of ICS therapy on direct healthcare costs. Factors with $95 \% \mathrm{Cl}$ for the variable ICS=always are shown. Each factor was calculated by a separate gamma regression model, adjusted for covariates and including the IPW (based on propensity scores).

After matching all-cause outpatient costs and total health care costs were similar in both ICS groups, whereas respiratory medication costs remained higher in the ICS group, in line with the previous finding. ${ }^{12}$ Conversely, all-cause inpatient costs tended to be lower in ICS patients. Due to the definition of A/B groups, this could not have been due to severe exacerbations but must have had other reasons. From the data available in COSYCONET, a more detailed analysis was not possible as the reason for utilization was not recorded. Irrespective of this, our findings indicate that the costs of ICS therapy in A/B patients require a detailed analysis.

Regarding outcome measures, the use of ICS was associated with better generic quality of life as measured by the EQ-VAS scale, in line with findings showing a deterioration of EQ-VAS in patients undergoing ICS withdrawal. ${ }^{37}$ This is remarkable, as among our ICS patients of GOLD groups A/B 72\% also received LABA/LAMA, ie a potent bronchodilator combination. Unfortunately, only 87 patients received ICS monotherapy or a combination with LAMA or LABA, and therefore, numbers were too low to draw reliable conclusions for patients with ICS but not triple therapy. In the propensity matching, we used mMRC and the single CAT questions as predictors but not the SGRQ that also measures COPD symptoms. The finding that the SGRQ subdomains showed no differences between ICS groups thus indicates that the matching for symptoms was adequate. ICS therapy was also associated with an increased $\mathrm{CO}$ diffusing capacity after matching. It is known that structural changes in the peripheral lung cannot be adequately represented by standard spirometric measurements, while diffusing capacity can be used for this purpose. Our observational results are in line with those of randomized controlled studies that showed an improvement of diffusing capacity during treatment with $\mathrm{ICS},{ }^{38}$ whereas spirometric values were not found to be significantly altered. ${ }^{39-41}$

Beyond the effects of ICS on the selected outcome measures, one of the findings of our study was the identification of predictors of ICS therapy. There were associations with exacerbation history and $\mathrm{FEV}_{1} \%$ predicted but also a higher symptom burden for the CAT items cough, phlegm, dyspnoea, confidence of leaving home, and sleep disturbance. The fact that only 5 of 8 items were predictors underlined our previous finding that the single CAT items carry different information. ${ }^{42}$ We used the single items as a substitute for informal questions that might be posed by the treating physician in the decision on ICS treatment, even when not using the CAT instrument. This assumption was in accordance with data showing that in the general practitioner setting, ICS treatment was re-initiated after withdrawal mainly due to respiratory symptoms. ${ }^{37}$ 


\section{Limitations and Strengths}

The analysis was based on cross-sectional data and naturally does not allow causal inferences. However, using the propensity score approach we aimed to transform the data set into one representing two matched groups as far as possible, and this was effective. Still, unobserved confounders might have influenced the decision on ICS therapy. We pooled data of visits 1 and 3, although there were small changes over time, and this was done for both outcome measures and predictors, wherever this made sense. The reason was that we wanted to maximize power by reducing variability, whereas the introduction of time effects in a repeatedmeasures design would have prevented the use of a wellestablished matching approach. An additional analysis with an adjusted repeated-measures design but without IPW matching yielded qualitatively similar results for the outcome measures; we thus consider the pooling as justified. In addition, the information regarding the eosinophilic phenotype of the patients could not be evaluated. However, we excluded patients with the comorbidity asthma, as well as patients with alpha 1-antitrypsin deficiency due to their high medication cost. ${ }^{43}$ Exacerbation history derived from self-reported information was sufficient for categorization into GOLD groups as in previous analyses of COSYCONET data but whether there was under-reporting, ${ }^{44,45}$ is not known. Moreover, the reasons for hospitalizations due to non-respiratory causes were not known, an information which might have been interesting in view of indirect positive effects of ICS on the heart. ${ }^{46,47}$ Unfortunately, no data on the prevalence of pneumonia or oral candidiasis were collected in COSYCONET, therefore no conclusions can be drawn regarding the known typical side effects of ICS. At least, no significant differences were observed with respect to the prevalence of osteoporosis (see Table 2). On the other hand, the strength of the study was the high quality of clinical, functional and health economic data in combination with a large data set, as well as the sophisticated data analysis by inverse probability weight matching.

\section{Conclusion}

In COPD patients of GOLD groups $\mathrm{A} / \mathrm{B}$, ICS treatment is considered inappropriate in most circumstances. We found that $\mathrm{A} / \mathrm{B}$ patients treated with ICS showed impairments in a number of functional and clinical measures compared to those without ICS. To identify the real ICS effects, we adjusted for the differences in predictors that might be used by physicians for therapeutic decisions. After adjustment, most of the differences in measures chosen as outcome disappeared. Still, ICS treatment was linked to improvements in generic quality of life and $\mathrm{CO}$ diffusing capacity, but also an increase in the costs of respiratory medication, without effect on total direct health care costs. These data indicate potential beneficial effects of ICS in a subgroup of COPD patients in GOLD groups A and B. However, future studies are needed to clearly define subgroups that might benefit from ICS.

\section{COSYCONET Study Group}

Andreas, Stefan (Lungenfachklinik, Immenhausen); Bals, Robert Universitätsklinikum des Saarlandes); Behr, Jürgen and Kahnert, Kathrin (Klinikum der Ludwig-MaximiliansUniversität München); Bahmer, Thomas (Universit ätsklinikum Schleswig Holstein) and Bewig, Burkhard (Städtisches Krankenhaus Kiel); Ewert, Ralf and Stubbe, Beate (Universitätsmedizin Greifswald); Ficker, Joachim H. (Klinikum Nürnberg, Paracelsus Medizinische Privatuniversität Nürnberg); Grohé, Christian (Ev. Lungenklinik Berlin); Held, Matthias (Klinikum Würzburg Mitte gGmbH, Standort Missioklinik); Behr, Jürgen and Henke, Markus (Asklepios Fachkliniken München-Gauting); Herth, Felix (Thoraxklinik Heidelberg gGmbH); Kirsten, Anne-Marie and Watz, Henrik (Pneumologisches Forschungsinstitut an der Lungenclinic Grosshansdorf $\mathrm{GmbH}$ ); Koczulla, Rembert (Schön Klinik Berchtesgadener Land); Kronsbein, Juliane (Berufsgenossenschaftliches Universitätsklinikum Bergmannsheil, Bochum); KropfSanchen, Cornelia (Universitätsklinikum Ulm); Lange, Christoph (Forschungszentrum Borstel); Pfeifer, Michael (Klinik Donaustauf); Randerath, Winfried J. (Wissenschaftliches Institut Bethanien e. V., Solingen); Seeger, Werner (Justus-Liebig-Universität Gießen); Studnicka, Michael (Uniklinikum Salzburg); Taube, Christian (Ruhrlandklinik gGmbH Essen); Timmermann, Hartmut (Hamburger Institut für Therapieforschung $\mathrm{GmbH}$ ); Alter, Peter and Vogelmeier, Claus (Universitätsklinikum Gießen und Marburg $\mathrm{GmbH}$, Standort Marburg); Welte, Tobias (Medizinische Hochschule Hannover); Wirtz, Hubert (Universitätsklinikum Leipzig).

\section{Data Sharing Statement}

The basic data are part of the German COPD cohort COSYCONET (www.asconet.net) and available upon request. The website of the network provides a detailed procedure for respective applications. The data can be obtained after the submission of a proposal that is 
evaluated by the steering committee. All results to which the manuscript refers are documented appropriately in the text, figures or tables.

\section{Ethics Approval and Consent to Participate}

All assessments were approved by the central (Marburg (Ethikkommission FB Medizin Marburg) and local (Bad Reichenhall (Ethikkommission bayerische Landesärz tekammer); Berlin (Ethikkommission Ärztekammer Berlin); Bochum (Ethikkommission Medizinische Fakultät der RUB); Borstel (Ethikkommission Universität Lübeck); Coswig (Ethikkommission TU Dresden); Donaustauf (Ethikkommission Universitätsklinikum Regensburg); Essen (Ethikkommission Medizinische Fakultät Duisburg-Essen); Gießen (Ethikkommission Fachbereich Medizin); Greifswald (Ethikkommission Universitätsmedizin Greifswald); Großhansdorf (Ethikkommission Ärztekammer SchleswigHolstein); Hamburg (Ethikkommission Ärztekammer Hamburg); MHH Hannover/Coppenbrügge (MHH Ethikko mmission); Heidelberg Thorax/Uniklinik (Ethikkommission Universität Heidelberg); Homburg (Ethikkommission Saarbrücken); Immenhausen (Ethikkommission Landesä rztekammer Hessen); Kiel (Ethikkommission ChristianAlbrechts-Universität zu Kiel); Leipzig (Ethikkommission Universität Leipzig); Löwenstein (Ethikkommission Landesärztekammer Baden-Württemberg); Mainz (Ethikkommission Landesärztekammer Rheinland-Pfalz); München LMU/Gauting (Ethikkommission Klinikum Universität München); Nürnberg (Ethikkommission FriedrichAlexander-Universität Erlangen Nürnberg); Rostock (Ethikkommission Universität Rostock); Berchtesgadener Land (Ethikkommission Land Salzburg); Schmallenberg (Ethikkommission Ärztekammer Westfalen-Lippe); Solingen (Ethikkommission Universität Witten-Herdecke); Ulm (Ethikkommission Universität Ulm); Würzburg (Ethikkommission Universität Würzburg)) ethical committees and written informed consent was obtained from all patients.

The study was based on 2741 patients recruited within the COSYCONET framework (ClinicalTrials.gov, Identifier: NCT01245933). For further information see Karch A, Vogelmeier C, Welte T, Bals R, Kauczor HU, Biederer J, Heinrich J, Schulz H, Glaser S, Holle R et al: The German COPD cohort COSYCONET: Aims, methods and descriptive analysis of the study population at baseline. Respir Med 2016, 114:27-37.

\section{Consent for Publication}

Within the ethical approval of COSYCONET, the participants of the study gave their consent to publish the data collected without reference to their person.

\section{Acknowledgments}

We are grateful to all COSYCONET study centers, especially to all study nurses, for their excellent and enduring work in data collection, as well as to all patients who were willing to participate in this study. COSYCONET is supported by the German Federal Ministry of Education and Research (BMBF) Competence Network Asthma and COPD (ASCONET) and performed in collaboration with the German Center for Lung Research (DZL). The project is funded by the BMBF with grant number 01 GI 0881, and is supported by unrestricted grants from AstraZeneca $\mathrm{GmbH}$, Bayer Schering Pharma AG, Boehringer Ingelheim Pharma $\mathrm{GmbH} \& \mathrm{Co}$. KG, Chiesi GmbH, GlaxoSmithKline, Grifols Deutschland GmbH, MSD Sharp \& Dohme $\mathrm{GmbH}$, Mundipharma $\mathrm{GmbH}$, Novartis Deutschland GmbH, Pfizer Pharma GmbH, Takeda Pharma Vertrieb $\mathrm{GmbH} \&$ Co. KG, Teva GmbH for patient investigations and laboratory measurements. For the present study, an additional grant for data management was given by Novartis Pharma GmbH. The funding body had no involvement in the design of the study, or the collection, analysis or interpretation of the data. We thank Dr. James Rooney for helpful comments.

\section{Disclosure}

Professor Tobias Welte reports grants from German Ministry of Research and Education, during the conduct of the study; personal fees from AstraZeneca, GSK, Novartis, and Chiesi, outside the submitted work. Professor Robert Bals reports grants from Bundesministerium für Bildung und Forschung, during the conduct of the study; outside the submitted work. Professor Claus F. Vogelmeier reports grants, personal fees from AstraZeneca, Boehringer Ingelheim, CSL Behring, Chiesi; grants from GlaxoSmithKline, Grifols, Menarini, Novartis, Nuvaira, and MeddUpdate, outside the submitted work. The authors declare that they have no other competing interests.

\section{References}

1. Halpin DMG, de Jong HJI, Carter V, Skinner D, Price D. Distribution, Temporal Stability and Appropriateness of Therapy of Patients With COPD in the UK in Relation to GOLD 2019. E Clin Med. 2019;14:32-41. doi:10.1016/j.eclinm.2019.07.003 
2. White P, Thornton H, Pinnock H, Georgopoulou S, Booth HP. Overtreatment of COPD with inhaled corticosteroids-implications for safety and costs: cross-sectional observational study. PLoS One. 2013;8(10):e75221. doi:10.1371/journal.pone.0075221

3. Jochmann A, Scherr A, Jochmann DC, et al. Impact of adherence to the GOLD guidelines on symptom prevalence, lung function decline and exacerbation rate in the Swiss COPD cohort. Swiss Med Wkly. 2012;142:w13567.

4. Roche N, Jebrak G, Caillaud D, et al. Real-life use of long-acting antimuscarinic agents following their approval for COPD treatment Eur Respir J. 2015;45(1):260-262. doi:10.1183/09031936.00131614

5. Roche N, Lepage T, Bourcereau J, Terrioux P. Guidelines versus clinical practice in the treatment of chronic obstructive pulmonary disease. Eur Respir J. 2001;18(6):903-908. doi:10.1183/ 09031936.01 .00213701

6. Tsiligianni I, Kampouraki M, Ierodiakonou D, Poulonirakis I, Papadokostakis P. COPD patients' characteristics, usual care, and adherence to guidelines: the Greek UNLOCK study. Int J Chron Obstruct Pulmon Dis. 2019;14:547-556. doi:10.2147/COPD.S185362

7. Geraets I, Schermer T, Kocks JWH, Akkermans R, Bischoff E, van den Bemt L. Primary care cohort study in the sequence of diagnosing chronic respiratory diseases and prescribing inhaled corticosteroids. NPJ Prim Care Respir Med. 2018;28(1):37. doi:10.1038/s41533-0180106-6

8. Urwyler P, Abu Hussein N, Bridevaux PO, et al. Predictive factors for exacerbation and re-exacerbation in chronic obstructive pulmonary disease: an extension of the Cox model to analyze data from the Swiss COPD cohort. Multidiscip Respir Med. 2019;14(1):7. doi:10.1186/s40248-019-0168-5

9. Graf J, Jorres RA, Lucke T. An analysis of guideline-adherent prescribing in a large national cohort (COSYCONET). Deutsches Ärzteblatt. 2018. 115(37):599.

10. Yang IA, Fong KM, Sim EH, Black PN, Lasserson TJ, Inhaled corticosteroids for stable chronic obstructive pulmonary disease. Cochrane Database Syst Rev. 2007;2:CD002991. doi:10.1002/ 14651858.CD002991.pub2

11. Price DB, Voorham J, Brusselle G, et al. Inhaled corticosteroids in COPD and onset of type 2 diabetes and osteoporosis: matched cohort study. NPJ Prim Care Respir Med. 2019;29(1):38. doi:10.1038/ s41533-019-0150-x

12. Fens T, van der Pol S, Kocks JWH, Postma MJ, van Boven JFM. Economic impact of reducing inappropriate inhaled corticosteroids use in patients with chronic obstructive pulmonary disease: ISPOR's guidance on budget impact in practice. Value Health. 2019;22 (10):1092-1101. doi:10.1016/j.jval.2019.05.006

13. Vogelmeier CF, Criner GJ, Martinez FJ, et al. Global Strategy for the Diagnosis, Management, and Prevention of Chronic Obstructive Lung Disease 2017 Report. GOLD Executive Summary. Am $J$ Respir Crit Care Med. 2017;195(5):557-582. doi:10.1164/ rccm.201701-0218PP

14. Turan O, Yemez B, Itil O. The effects of anxiety and depression symptoms on treatment adherence in COPD patients. Prim Health Care Res Dev. 2014;15(3):244-251. doi:10.1017/ S1463423613000169

15. Yohannes AM, Alexopoulos GS. Depression and anxiety in patients with COPD. Eur Respir Rev. 2014;23(133):345-349. doi:10.1183/ 09059180.00007813

16. Kahnert K, Alter P, Young D, et al. The revised GOLD 2017 COPD categorization in relation to comorbidities. Respir Med. 2018;134:79-85. doi:10.1016/j.rmed.2017.12.003

17. Karch A, Vogelmeier C, Welte T, et al. The German COPD cohort COSYCONET: aims, methods and descriptive analysis of the study population at baseline. Respir Med. 2016;114:27-37. doi:10.1016/j. rmed.2016.03.008
18. Vogelmeier CF, Criner GJ, Martinez FJ, et al. Global strategy for the diagnosis, management, and prevention of chronic obstructive lung disease 2017 Report: GOLD Executive Summary. Eur Respir J. 2017;49(3):1700214. doi:10.1183/13993003.00214-2017

19. Celli BR, Cote CG, Marin JM, et al. The body-mass index, airflow obstruction, dyspnea, and exercise capacity index in chronic obstructive pulmonary disease. $N$ Engl $J$ Med. 2004;350(10):1005-1012. doi:10.1056/NEJMoa021322

20. Budweiser S, Meyer K, Jorres RA, Heinemann F, Wild PJ, Pfeifer M. Nutritional depletion and its relationship to respiratory impairment in patients with chronic respiratory failure due to COPD or restrictive thoracic diseases. Eur J Clin Nutr. 2008;62(3):436-443. doi:10.1038/ sj.ejcn. 1602708

21. Hagstromer M, Oja P, Sjostrom M. The International Physical Activity Questionnaire (IPAQ): a study of concurrent and construct validity. Public Health Nutr. 2006;9(6):755-762. doi:10.1079/ PHN2005898

22. Lucke T, Herrera R, Wacker M, et al. Systematic Analysis of SelfReported Comorbidities in Large Cohort Studies - A Novel Stepwise Approach by Evaluation of Medication. PLoS One. 2016;11(10): e0163408. doi:10.1371/journal.pone.0163408

23. Criee CP, Baur X, Berdel D, et al. [Standardization of spirometry: 2015 update. Published by German Atemwegsliga, German Respiratory Society and German Society of Occupational and Environmental Medicine]. Pneumologie. 2015;69(3):147-164. doi:10.1055/s-0034-1391345

24. Celli BR, Decramer M, Wedzicha JA, et al. An official American Thoracic Society/European Respiratory Society statement: research questions in COPD. Eur Respir J. 2015;45(4):879-905. doi:10.1183/ 09031936.00009015

25. Stanojevic S, Graham BL, Cooper BG, et al. Official ERS technical standards: global Lung Function Initiative reference values for the carbon monoxide transfer factor for Caucasians. Eur Respir J. 2017;50(3):1700010. doi:10.1183/13993003.00010-2017

26. Quanjer PH, Tammeling GJ, Cotes JE, Pedersen OF, Peslin R, Yernault JC. Lung volumes and forced ventilatory flows. Report Working Party Standardization of Lung Function Tests, European Community for Steel and Coal. Official Statement of the European Respiratory Society. Eur Respir J Suppl. 1993;16:5-40. doi:10.1183/ $09041950.005 \mathrm{~s} 1693$

27. Byng D, Lutter JI, Wacker ME, et al. Determinants of healthcare utilization and costs in COPD patients: first longitudinal results from the German COPD cohort COSYCONET. Int J Chron Obstruct Pulmon Dis. 2019;14:1423-1439. doi:10.2147/COPD.S201899

28. Austin PC, Stuart EA. Moving towards best practice when using inverse probability of treatment weighting (IPTW) using the propensity score to estimate causal treatment effects in observational studies. Stat Med. 2015;34(28):3661-3679. doi:10.1002/sim.6607

29. Global initiative for chronic obstructive lung disease. 2021 GOLD reports. Available from: https://goldcopd.org/2021-gold-reports. Accessed April 8, 2021.

30. Vogelmeier C, Buhl R, Burghuber O, et al. S2k-Leitlinie zur Diagnostik und Therapie von Patienten mit chronisch obstruktiver Bronchitis und Lungenemphysem (COPD). Pneumologie. 2018;72 (4):253-308. doi:10.1055/s-0043-125031

31. Evidence reviews for the length of corticosteroid use during exacerbationsChronic obstructive pulmonary disease in over 16s: diagnosis and managementEvidence review JNICE Guideline, No. 115NICE Guideline Updates Team (UK).London: National Institute for Health and Care Excellence (UK); 2019. ISBN-13: 978-1-4731-3468-3

32. Souliotis K, Silva Miguel L, Hillas G, et al. The cost-saving switch from inhaled corticosteroid-containing treatments to dual bronchodilation: a two-country projection of epidemiological and economic burden in chronic obstructive pulmonary disease. Ther Adv Respir Dis. 2020;14:1753466620926802. doi:10.1177/1753466620926802 
33. Ernst P, Saad N, Suissa S. Inhaled corticosteroids in COPD: the clinical evidence. Eur Respir J. 2015;45(2):525-537. doi:10.1183/ 09031936.00128914

34. Latorre M, Novelli F, Vagaggini B, et al. Differences in the efficacy and safety among inhaled corticosteroids (ICS)/long-acting beta2-agonists (LABA) combinations in the treatment of chronic obstructive pulmonary disease (COPD): role of ICS. Pulm Pharmacol Ther. 2015;30:44-50. doi:10.1016/j.pupt.2014.10.006

35. Rabe KF, Martinez FJ, Ferguson GT, et al. Triple Inhaled Therapy at Two Glucocorticoid Doses in Moderate-to-Very-Severe COPD. $N$ Engl J Med. 2020;383(1):35-48. doi:10.1056/NEJMoa1916046

36. Ferguson GT, Rabe KF, Martinez FJ, et al. Triple therapy with budesonide/glycopyrrolate/formoterol fumarate with co-suspension delivery technology versus dual therapies in chronic obstructive pulmonary disease (KRONOS): a double-blind, parallel-group, multicentre, Phase 3 randomised controlled trial. Lancet Respir Med. 2018;6(10):747-758.

37. van den Bemt L, van den Nieuwenhof L, Rutjes A, et al. Pragmatic trial on inhaled corticosteroid withdrawal in patients with COPD in general practice. NPJ Prim Care Respir Med. 2020;30(1):43. doi:10.1038/s41533-020-00198-5

38. Sandek K, Bratel T, Lagerstrand L. Effects on diffusing capacity and ventilation-perfusion relationships of budesonide inhalations for 2 months in chronic obstructive pulmonary disease (COPD). Respir Med. 2001;95(8):676-684. doi:10.1053/rmed.2001.1124

39. Vestbo J, Sorensen T, Lange P, Brix A, Torre P, Viskum K. [Longterm effect of inhaled budesonide in patients with mild to moderate chronic obstructive lung disease. The Osterbro Study]. Ugeskr Laeger. 2000;162(4):493-497.
40. Vestbo J, Sorensen T, Lange P, Brix A, Torre P, Viskum K. Long-term effect of inhaled budesonide in mild and moderate chronic obstructive pulmonary disease: a randomised controlled trial. Lancet. 1999;353(9167):1819-1823. doi:10.1016/S0140-6736(98)10019-3

41. Pauwels RA, Lofdahl CG, Laitinen LA, et al. Long-term treatment with inhaled budesonide in persons with mild chronic obstructive pulmonary disease who continue smoking. European Respiratory Society Study on Chronic Obstructive Pulmonary Disease. N Engl J Med. 1999;340 (25):1948-1953. doi:10.1056/NEJM199906243402503

42. Marietta von Siemens S, Alter P, Lutter JI, et al. CAT score single item analysis in patients with COPD: results from COSYCONET. Respir Med. 2019;159(105810):105810. doi:10.1016/j.rmed.2019.105810

43. Karl FM, Holle R, Bals R, et al. Costs and health-related quality of life in Alpha-1-Antitrypsin Deficient COPD patients. Respir Res. 2017;18(1):60. doi:10.1186/s12931-017-0543-8

44. Pavord ID, Jones PW, Burgel PR, Rabe KF. Exacerbations of COPD. Int J Chron Obstruct Pulmon Dis. 2016;11(Spec Iss):21-30. doi:10.2147/COPD.S85978

45. Jones PW, Lamarca R, Chuecos F, et al. Characterisation and impact of reported and unreported exacerbations: results from ATTAIN. Eur Respir J. 2014;44(5):1156-1165. doi:10.1183/09031936.00038814

46. Shin J, Yoon HY, Lee YM, Ha E, Lee JH. Inhaled corticosteroids in COPD and the risk for coronary heart disease: a nationwide cohort study. Sci Rep. 2020;10(1):18973. doi:10.1038/s41598-020-74854-8

47. Huiart L, Ernst P, Ranouil X, Suissa S. Low-dose inhaled corticosteroids and the risk of acute myocardial infarction in COPD. Eur Respir J. 2005;25(4):634-639. doi:10.1183/09031936.05.00079004

\section{Publish your work in this journal}

The International Journal of COPD is an international, peer-reviewed journal of therapeutics and pharmacology focusing on concise rapid reporting of clinical studies and reviews in COPD. Special focus is given to the pathophysiological processes underlying the disease, intervention programs, patient focused education, and self management protocols. This journal is indexed on PubMed Central, MedLine and CAS. The manuscript management system is completely online and includes a very quick and fair peer-review system, which is all easy to use. Visit http://www.dovepress.com/testimonials.php to read real quotes from published authors. 